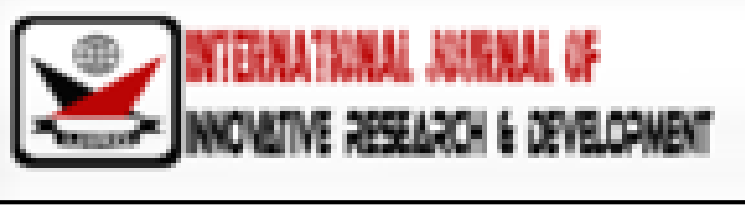

ISSN 2278 - 0211 (Online)

\title{
Evaluation of Effectiveness of Early Recovery Strategies in Use against Drought in Turkana Central Sub County, Kenya
}

Godfrey Engor
Masters Student, Department of Emergency Management Studies
Ferdinand Makhanu Nabiswa
Lecturer, Department of Emergency Management Studies
Edward M. Mugalavai
Lecturer, Department of Disaster Management and Sustainable Development
Masinde Muliro University of Science and Technology

\begin{abstract}
:
Drought has significant impacts in climate sensitive sectors in ASAL areas of Kenya. Despite the existence of drought early recovery strategies, Turkana central suffers from extreme drought conditions with negative implications on livelihood security. The study presents the effects of drought on livelihood options with great emphasis on the early recovery strategies such as crop farming under irrigation, livelihood diversification, sending children to school, social protection programs, livestock keeping/migration and social support network. The analysis undertaken in this study was to identify the effectiveness of the drought early recovery strategies used by the communities in Turkana central sub County to augment shortfalls occasioned by drought episodes. During the study, drought early recovery strategies were analyzed to determine whether they were able to withstand, cope and recover from the effects of drought.
\end{abstract}

Keywords: Drought, early recovery strategies, ASAL.

\section{Introduction}

Drought is expected to have significant impacts in most of the climate sensitive sectors in Kenya. In the ASALs, for example, frequent droughts are associated with the deterioration of livestock conditions, increased incidences of diseases, and livestock deaths, altered herd structure, and a collapse of livestock markets (Speranza, 2010). Extreme drought conditions have serious negative effects on the livelihood security of most pastoralists in Turkana central sub county. This is compounded by the inability of communities to respond to extreme environmental conditions, in addition to the challenges faced with prolonged drought events (Handley, 2012).

Mureithi, (2012) asserts that the Turkana community uses coping strategies that are inadequate for vulnerability reduction due to the changing global environment characterized by climate change, evolving socio- political and economic circumstances. Most studies dealing with drought have concentrated more on the traditional coping and adaptation strategies among the Turkana pastoralists (Ouma, 2011; Mureithi, 2012; Opiyo et. al., 2015). This approach can be misleading in the sense that the pastoralists' communities social, political and economic needs keep on changing and so are their different strategies against drought impacts. This study therefore sought to investigate the drought early recovery strategies and their effectiveness in influencing sustainable livelihood options among households in Turkana Central Sub County.

\section{Conceptual Framework}

Watts and Bohle model examines external processes not as geographical and physical characteristics, but as the wider scale, political, economic and social processes that affect individual capacity to respond and cope with disaster events (Watts and Bohle, 1993; Villagrán, 2006). Through this approach, access and control over assets, including economic, socio-political, infrastructural, ecological and personal, is recognized as a key process affecting vulnerability levels. In this sense, those individuals and groups who have control over key assets have increased their coping capacities to disaster events, thereby reducing their vulnerability. This model of vulnerability is effective because it provides not only an explanation of vulnerability, but also some of the key causes and origins (Villagrán, 2006).

The Watts and Bohle (1993) model also incorporates the geographical importance of place through the interaction and manifestation of various processes at the local scale. Vulnerability makes it more or less likely that an individual will succumb to effects of drought if a certain severity is encountered. Vulnerability can also be conceptualized as situational factors, such as low socio-economic status or predisposition to drought conditions as already seen is this 
case with ASAL communities in Turkana County. In the Watts and Bohle model, the external processes are still related to the exposure to shocks and stressors, and the following influence these external factors:

- Human-Ecological Perspectives: these perspectives focus on population dynamics and the capacities of individuals, groups and communities to manage their surrounding environment.

- Entitlement Theory: argues that those individuals, groups and communities who are unable or incapable of obtaining and managing their assets through legitimate economic means have increased vulnerabilities

- Political Economy Approaches: examines the social inequalities and injustices that lead to struggles and conflicts between classes of people. This approach relates vulnerability to exposure to social inequalities and lack of control of assets.

The following influence the internal processes, or coping abilities, of individuals and groups:

- Action Theory Approaches: examines the means and ways incorporated by people, which allows them to act, either by free will, or as a consequence of societal, governmental or economic constraints.

- Models of Access to Assets: These models relate vulnerability to control over their assets and provide techniques through which individuals can mitigate their vulnerability through access to resources and assets of a different nature.

- Crisis and Conflict Theory: examines how control over resources and assets, as well as capacities to manage resources and assets through crises can influence vulnerabilities.

Watts and Bohle, (1993) expanded the Chambers model of vulnerability through the incorporation of their view of vulnerability as a "multi-layered and multi- dimensional social space defined by the political, economic, and institutional capabilities of people in specific places and times" (Villagrán, 2006, p. 12; Watts and Bohle, 1993). While the Watts and Bohle (1993) model is similar to the Chambers model of internal and external processes of vulnerability, the factors, which influence these processes, have been enhanced. As depict in figure 2.4, the Watts and Bohle model of vulnerability.

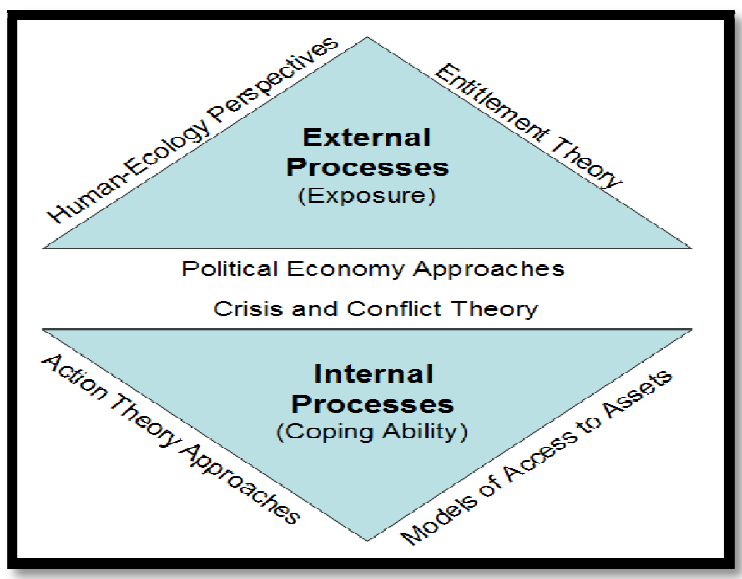

Figure 1: Watts and Bohle Model of Vulnerability Source: Watts and Bohle (1993)

\section{Methodology}

The study used structured household questionnaires, participant observation checklists, key informant interview guides and focus group discussions to collect both quantitative and qualitative primary data. Secondary data included content analysis obtained from publications, journals, and internet access. A sample size of 384 households was determined using fisher's formula. The study utilized proportionate, quota sampling for the and purposive sampling. All the quantitative data collected was analyzed using Excel and SPSS version 20 to generate descriptive statistics.

\section{Findings}

\subsection{Crop Farming as an Early Recovery Strategy}

The study sought to find out the effectiveness of crop farming as an early recovery strategy against drought. The household heads were asked to state whether crop farming was either sustainable or beneficial, as an early recovery strategy. Based on their perceptions, the results were as shown in Figure 2.

\begin{tabular}{|c|c|c|}
\hline & Frequency & Percent \\
\hline Sustainable & 223 & 58.0 \\
\hline Beneficial & 161 & 42.0 \\
\hline Total & 384 & 100.0 \\
\hline
\end{tabular}

Figure 2: Crop Farming as an Early Recovery Strategy Source: Field Data, 2019

The Findings in Figure 2 revealed that 58\% (223) stated that crop farming was a sustainable early recovery strategy against drought with $42 \%$ (161) opining that crop farming was beneficial as an early recovery strategy. Based on 
the results it was evident that majority of the household heads were of the opinion that crop farming was an effective early recovery strategy against drought in Turkana Central Sub County. In support of the results from the household heads, a key informant from the County government of Turkana revealed that:

Crop farming had become an important source of livelihood in Turkana County. The farming types were mainly early maturing forms of grain crops such as sorghum and maize breeds. Settled farmers and agro-pastoralists grow maize, sorghum, and vegetables. The need for grains by pastoral household is rapidly growing as the milk production decreases and the need for energy rich foods rises. Farming was also supported by the county government efforts and other development partners through irrigation systems and provision of farm inputs such as seeds and farm implements (Interview with an official from the Ministry of Agriculture and Irrigation, Turkana County, 20 th June 2019).

Additionally, it was found that, during drought, some households depended on farming for up to $100 \%$ of their household needs as revealed during the Interview, where one of the Key informants opined that:

Many households have benefited a lot from crop farming to cope with the effect of drought. We are able to afford at least one meal per day courtesy of engaging in crop farming (Interview with an Assistant Chief, 10 ${ }^{\text {th }}$ June 2019).

The results were further supported by FGD participant views in Kerio Sub-location. One of the participants opined that:

With proper strategies, crop production can achieve maximum sustainability through support and promotion of irrigation technology, best farming practices and investing in agro-ecological zones (an FGD Participant from Kerio, 11, June 2019).

In agreement with the findings, the Turkana County LRA Report (2017) revealed that Crop production contributes 60 and 40 percent to food and household income respectively. The report further suggests that the County is dependent on long-rains accounting for approximately 70 percent of annual crop production with maize, cowpeas and sorghum being the major crops grown.

The findings of this study are also in agreement with Ogenga et al. (2018) who argued that Maize crop is considered the staple food in most parts of Kenya, thereby indicating that availability of this particular food crop means there is food security. The scholars further argue that, Maize crop tends to experience extreme sensitivity to water deficit, during a short critical period, from flowering to beginning of grain filling phase, maize crops are more sensitive to the drought related climatic factors than other crop types in water stressed regions yet in the eyes of the rural small scale farmers, lack of maize means hunger and famine. In this regard, Irrigation and the use of fast maturing crops is a possible sustainable solution to drought problems in Turkana Central sub County since the issues of hunger and famine will be seen as matters of the past in situations where crop farming is embraced.

\subsection{Livestock Migration as an Early Recovery Strategy}

The study sought to find out the effectiveness of livestock Migration as an early recovery strategy against drought in Turkana Central Sub-County. The household heads were asked to state whether Livestock migration was either sustainable or beneficial as an early recovery strategy. Based on their perceptions, the results were as shown in Figure 6.1.

The results in Figure 6.1 revealed that 84\% (322) of the household heads opined that livestock migration was beneficial while $16 \%$ (62) suggesting that it was sustainable. In this regard, it emerged from the study that in as much as majority of the household heads viewed livestock migration as beneficial, they however, did not think it was sustainable as an early recovery strategy against drought.

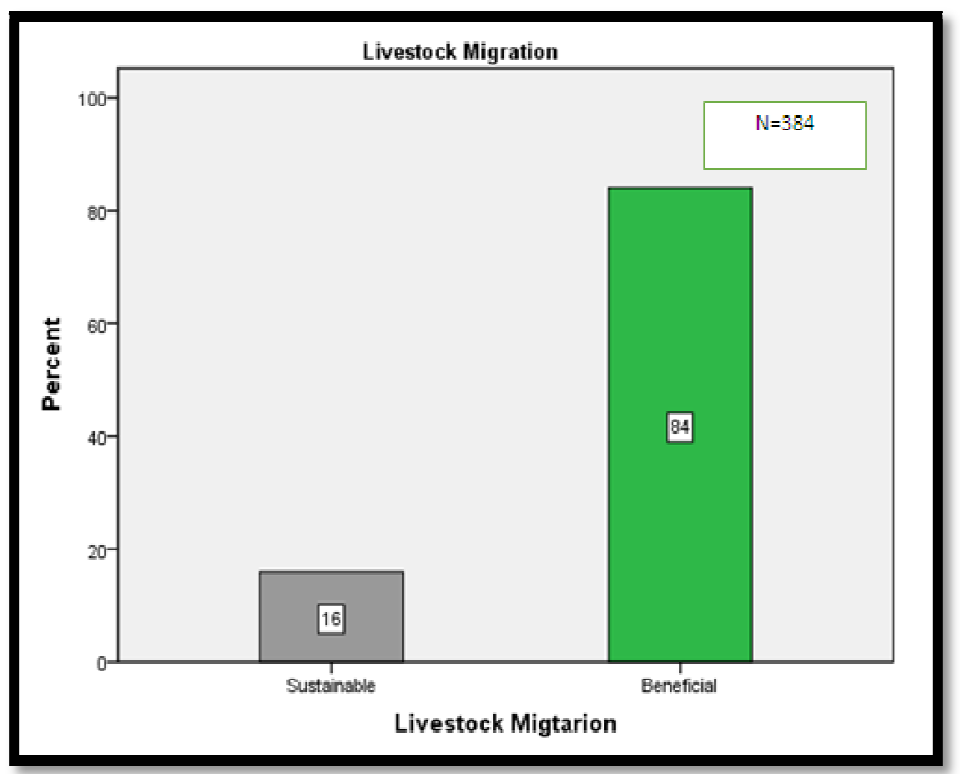

Figure 3: Livestock Migration as an Early Recovery Strategy Source: Field Data, 2019 
However, the Findings from FGDs were twofold, with some concurring that livestock migration was an effective early recovery strategy while others said that it needed to be embraced with caution since such movements caused conflicts that in most instances resulted into loss of lives for both humans and livestock.

In support of livestock migration, one of the discussants for instance said that;

Livestock migration has resulted to reduction in the loss of livestock as a result of drought and scarcity of water and pasture. During this time, animals can be migrated to resource rich areas where they could calf, increase their productivity and improve their general body condition which when sold could fetch good prices for the households to buy food. (FGD Participant at Nang'olekuruk, on 13/06/2019).

On the other hand, another discussant from a different FGD was of the opinion that livestock migration was to be embraced with caution due to the challenges it had been associated with in the past, He said that:

Although livestock migration has helped the pastoralist community by saving animals from dying due to drought, we must be alive to the fact that it has also made us lose lives due to conflicts occasioned by competition over water and pasture resources (FGD Participant at Soweto, on 20/06/2019).

Despite its immense benefits as espoused by the respondents in this study, mobility is, however, affected by many factors. These include the type of relations that exist between local groups, which live in or around drought refuge areas; long, distance movement, which results in heavy loss of livestock; the existence of livestock disease risks, which delay movement to drought-refuge areas or result in heavy losses of livestock (Ahmed et al, 2002).

The findings of the study were also in agreement with studies from Watson and van Binsbergen (2006) which suggested that Turkana pastoralists, like other nomadic communities, have traditionally used risk-spreading strategies over the years that include moving livestock to access the best quality pasture and water available, keeping species-specific herds to take advantage of the heterogeneous nature of their disequilibrium environment, and diversifying economic strategies to include agriculture, wage labour, and beekeeping among others.

\subsection{Food for School Going Children as an Early Recovery Strategy}

The study sought to find out the effectiveness of Education as an early recovery strategy against drought in Turkana Central Sub-County. The household heads were asked to state whether their Children going to school was either sustainable or beneficial, as an early recovery strategy during drought period. Based on their perceptions, the results were as shown in Figure 6.2.

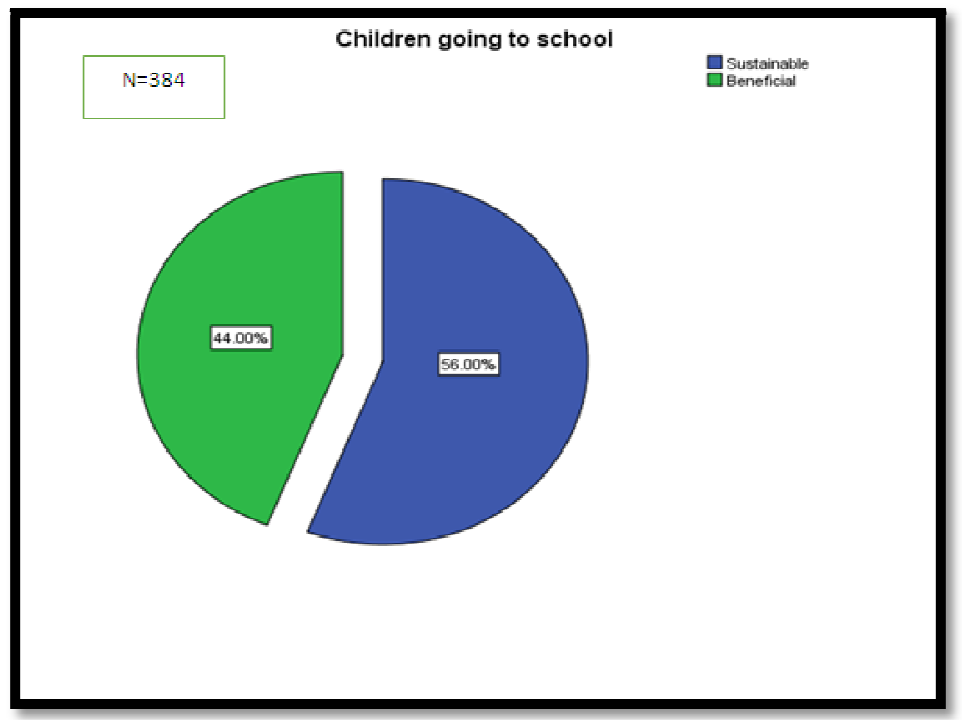

Figure 4: Food for Children Going to School Source: Field Data, 2019

The findings in Figure 6.2 revealed that 56\% (215) of the household heads opined that Education (their Children going to School) was a sustainable early recovery strategy against drought while 44\% (169) suggested that it was beneficial.

In support of the results from the household heads, an assistant Chief said that:

In my sub-location, it is evident that those homesteads where people are more educated and working, I can attest that the effects of drought are normally not severe as compared to those with little or no education. This is because those who are educated are more economically independent and as such are able to support their families during these hard times (Interview with an Assistant Chief on 10 th June, 2019).

During FGDs, it emerged that some parents took their children to school to get food especially during drought situations. This therefore, relieved them the burden of fending for their children during the period of scarcity. One of the discussants said that:

School going children are somehow well-off during school days but during weekends and school holidays, they face the wrath of drought just like any other family member in the household (FGD Participant from Soweto, 20 th June, 2019). 
In support of the results from the FGDs, an interview with an official from Mary Meals an NGO based in Lodwar, revealed that it was useful to provide food to school going children as a way of encouraging them to go school especially during drought situations. This eventually led to increased mean enrolment age in schools and thus guaranteed access to education for the pastoralists' children. The official further stated that that food offered in schools were balanced in terms of nutritional requirements and thus offered school going children low chances of suffering from malnutrition related conditions.

The findings agree with the Turkana County LRA report (2017) which confirmed that all schools in Turkana County are beneficiaries of School feeding programme either through Cash Transfers to Schools or regular School Feeding Programmes. The same report also revealed that availability of food in the schools had led to a significant increase in enrolment rates of school going children at 71.5 percent in 2017 as compared to only $32 \%$ of the school age children are enrolled in school in 2012 (Migosi et al, 2012).

It is therefore important to note that Education as an early recovery strategy has a huge impact based on its sustainability to the household heads. Education has both short term and long-term benefits that have proved to be beneficial and at the same time shown that it is a more sustainable recovery strategy against drought. This has also been due to the realization by pastoralist communities that sending children to school to acquire education and training is as an essential strategy to facilitate income diversification for pastoral households.

\subsection{Informal Trade as an Early Recovery Strategy}

The study sought to find out the effectiveness of informal trade as an early recovery strategy against drought in Turkana Central Sub-County. The household heads were asked to state whether informal trade was either sustainable or beneficial, as an early recovery strategy. Based on their perceptions, the results were as shown in Figure 6.3. The results in Figure 6.3 revealed that $90 \%$ (345) of the household heads were of the opinion that informal trade was beneficial as an Early recovery strategy against drought, while 10\% (39) said it was sustainable.

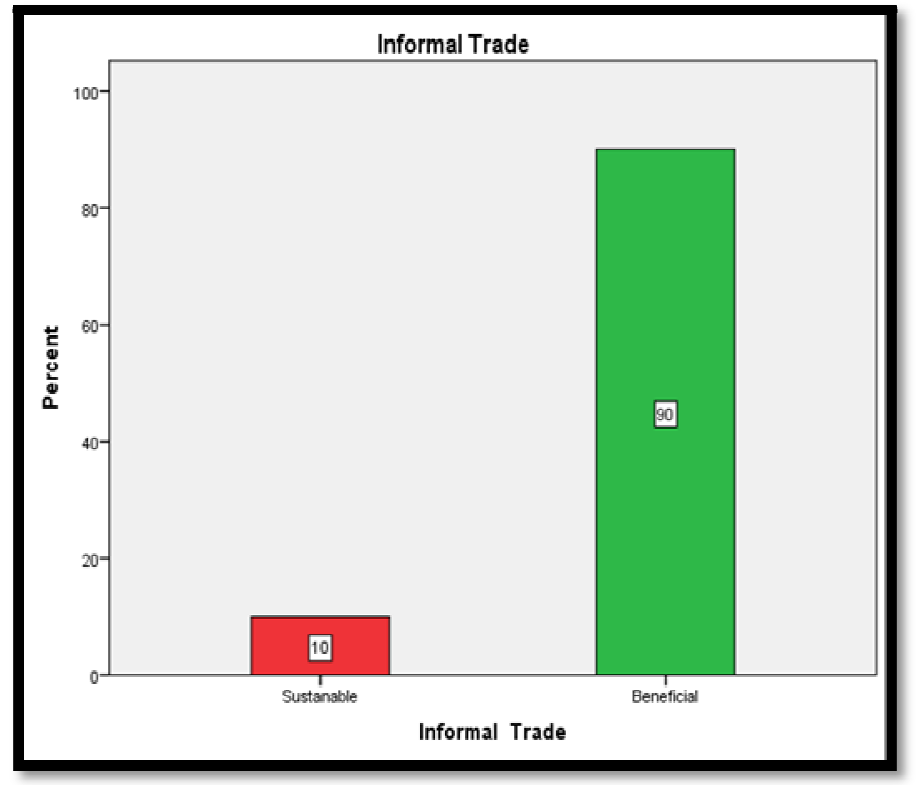

Figure 5: Informal Trade as an Early Recovery Strategy Source: Field Data, 2019

In all the 8 FGDs, it was revealed that informal trade such as selling of charcoal, basketry/weaving, beadwork, tobacco, alcohol, butchery was a common source of livelihood in Turkana Central Sub County. Some traders also engaged in retail trade, which ensured availability of some foodstuff like sugar to the local community during drought period. It was revealed that some of the households were dependent on traders to sell their livestock products and crop produce during drought period. Therefore, engaging in trading as an effective early recovery strategy was beneficial to both the buyer and seller.

These observations were corroborated by the opinion from a sub-county administrator who indicated:

Presence of increased trading activities in the sub county has been attributed to the increase of drought in the area. Livestock and farm products have been traded as an early recovery strategy. Women are engaging in non-ruminant trade especially poultry during drought and the proceeds are utilized to buy foodstuff for household consumption. Artisan trading activities such as selling of beads to other communities is also common a sub-county administrator (20 th June, 2019).

On the other hand, informal trading was not sustainable but beneficial as an early recovery strategy. The harsh economic times have resulted to some of the traders incurring losses due to high taxation and expenses in conducting businesses.

In some cases, some of them have been forced to close business due to insecurity and low sales volume. The respondents who have engaged in retail trading before also indicated that doing business is difficult especially during drought as most of the household lack cash and therefore, choose to get products on credit. In some cases, as it was 
revealed, some of them fail to clear their debt and denied that goods on credit also results to negative publicity. Therefore, petty trading was not sustainable and at the same time beneficial to the communities in Turkana County during drought. Those who engaged in charcoal selling also indicated that the trade is not sustainable because there have been a lot of effort to conserve environment. It was revealed during the interview that; charcoal burning is not encouraged as it has negative effects on the environment. Therefore, as an early recovery strategy, trading activities offer limited options to the community in Turkana County.

\subsection{Social Support Networks and an Early Recovery Strategy}

The study sought to find out the effectiveness of social support networks as an early recovery strategy against drought in Turkana Central Sub-County. The household heads were asked to state whether of social support networks was either sustainable or beneficial, as an early recovery strategy. Based on their perceptions, the results were as shown in Figure 6.4.

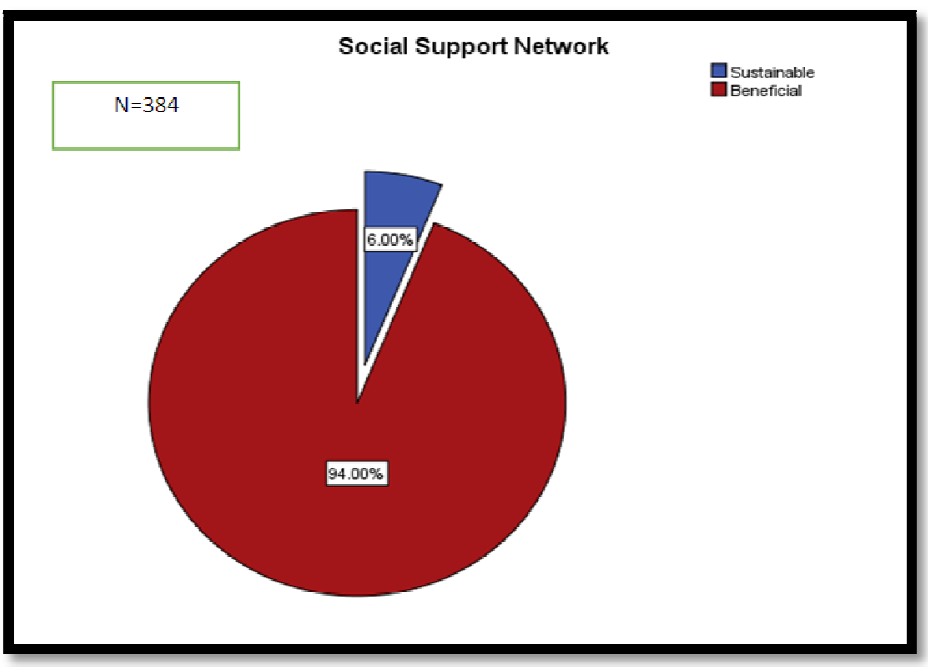

Figure 6: Social Support Networks

Source: Field Data, 2019

The results in Figure 6.4 revealed that 94\% (361) of the household heads indicated that social support networks were beneficial as an early recovery strategy against drought while 6\% (23) indicated that it was sustainable. The results revealed that social support was beneficial but not sustainable as an early recovery strategy against drought in the county. During interviews, FGD and questionnaire administration, it was noted that there was evidence of social support from NGOs, Governments, friends, relative and welfare groups which some of the respondents depended on during drought period. However, this study noted that it was not highly effective as an early recovery strategy in Turkana County because of its seasonality.

The FGDs further revealed that that it was useful during drought as households were able to access goods and services, which would otherwise not be accessible due to drought. It was revealed that households accessed foodstuff from friends and relatives and in some cases, children were sent to their relatives for some time during drought period. Therefore, the usefulness of social support was evident as it ensured family member can access a meal in day. It was also moderately important and beneficial. It was noted that some households received social support from welfare groups and women merry go round during drought. The researcher noted that, increase in CBOs and other social groups are as a result of their importance in Turkana community during drought period. Members, especially women are able to get help from their group to educate their children, health issues and also to buy food for their household.

The study revealed that social support especially from the government, NGOs and well-wishers is important in Turkana due to the low socio-economic status in the county. Majority of the household live below the poverty line and the effects of drought worsen the situation forcing them to depend on social support from government, NGOs and development partners.

The interview indicated that even during non-drought periods some households still depend on social support such as cash transfers for the most vulnerable members of society for survival. However, it was not sustainable to depend on social support.

During the interviews, one of Ward administrators opined that;

Depending on social support is not an effective early recovery strategy against drought because you are under the mercy of the source of support. It also leads to the dependency syndrome and laziness among the community members. These coping strategies should be substituted with other coping/recovery strategies for sustainable development' (Interview with Ward Administrator 20th June, 2019).

Based on the findings it was evident that social support was not sustainable in the long term and the results from the FGD revealed that some households had been crying for help in presence or absence of drought in the area. It was also noted that some form of social support such as getting food stuff on credit or borrowing money were not effective as they increase households' debt burden. This forces them to spend large proportion of their income in repaying debt thereby forming a cycle of borrow-pay, which hinders investment in other early recovery strategies such as trade and livelihood 
diversification. The study further asked the discussant to rank effectiveness of various social support groups in Turkana central sub county.

\section{Conclusion}

Based on the third specific objective the study concludes that the strategies used against drought were effective in reducing the immediate impacts of the drought but some of these strategies were unsustainable in the long term to find a lasting solution. Among the early recovery strategies education and crop production emerged as sustainable drought recovery strategies, livestock migration, informal trade and social support emerged as short-term solutions. Therefore, it is clear that majority of drought recovery strategies are short-term and reactive and hence not sustainable.

The overall conclusion of the study was that that drought remains a potent threat to the fragile and local economies such as livestock keeping and crop farming in Turkana central sub county. It was therefore evidently clear that drought has had profound effects on livelihood options in Turkana central sub county as it had affected critical livelihoods activities such as crop farming, livestock keeping, social support networks, livelihood diversification activities, and petty trade among others. It also had a profound effect on the environment, health condition of people and livestock, household income sources, peace and security.

\section{Recommendation}

Finally, the study recommends that there is the need for both county and national governments to invest a significant proportion of their resources in water harvesting strategies, which can be used not only for livestock and for domestic use during drought period, but can also be used for irrigation purposes.

\section{References}

i. Bohle, H. G., Downing, T. E., and Watts, M. J. 1994. Climate change and social vulnerability: toward a sociology and geography of food insecurity. Global Environmental Change, 4(1):37-48.

ii. Handley, C.S. (2012) No one can kill the drought: Understanding complexity in the relationship between drought and conflict amongst pastoralists in northern Kenya. Durham theses, Durham University

iii. Mureithi, J. (2012): A thesis titled "Causes and Management of Drought Vulnerability to drought in Turkana County"

iv. Ogenga, J.0, Mugalavai E.M \& Nyandiko, N. O. (2018) Impact of Rainfall Variability on Food production under Rainfed Agriculture in Homa Bay County, Kenya. International Journal of Scientific and Research Publications, Volume 8, Issue 8, August 2018

v. Opiyo, Francis \& Wasonga, Oliver \& Nyangito, Moses \& Schilling, Janpeter \& Munang, Richard. (2015). Drought Adaptation and Coping Strategies Among the Turkana Pastoralists of Northern Kenya. International Journal of Disaster Risk Reduction. 6. 10.1007/s13753-015-0063-4.

vi. Ouma, C. (2011): Thesis titled Assessment of the Post Drought Recovery Strategies among Pastoralists in Turkana Central District.

vii. Speranza, C.I. 2010. Drought coping and adaptation strategies: Understanding adaptations to climate change in agro-pastoral livestock production in Makueni District, Kenya. European Journal of Development Research 22(5): 623-642.

viii. Watson, D., and J. van Binsbergen. (2006). Life beyond pastoralism: Livelihood diversification opportunities for pastoralists in Turkana District, Kenya. ILRI (International Livestock Research Institute) brief. 